\title{
UMA PEDAGOGIA MULTIDISCIPLINAR, INTERDISCIPLINAR OU TRANSDISCIPLINAR PARA O ENSINO/APRENDIZAGEM DA FÍSICA
}

\author{
Ítalo Batista da Silva ${ }^{1}$, Otávio Augusto de Oliveira Tavares ${ }^{2}$ \\ ${ }^{1}$ Graduando em Licenciatura Plena em Física (CEFET-RN); \\ ibsfisica@hotmail.com \\ ${ }^{2}$ Mestre (PUC-RS) e Doutor em Educação Plena (UFRN), Professor do CEFET-RN; \\ otavio@cefetrn.br
}

Recebido em agosto de 2004 e Aceito em abril de 2005

\begin{abstract}
RESUMO
A Física é uma Ciência que estuda os fenômenos da natureza, procurando discuti-los, descobrir suas causas, como eles influenciam na nossa vida, sendo também uma disciplina do currículo escolar. Constatando a importância da Física, a dificuldade dos professores para lecioná-la mais formalmente de forma contextualizada/interativa, propõe-se três níveis de prática pedagógica: Multidisciplinaridade; Interdisciplinaridade e Transdisciplinaridade. Essas abordagens têm como objetivos: tornar o Ensino/Aprendizagem da Física mais dinâmico; identificar as dificuldades apresentadas pelos alunos/professores nesse processo; propor métodos para estruturar os conceitos dessa disciplina e proporcionar uma aprendizagem da física de forma interativa. A essencialidade da Física no currículo escolar, sua importância para a Educação, assim como, sua contextualização/globalização dos conteúdos, competências a serem desenvolvidas, uma prática pedagógica que reúne tais características é justamente a Interdisciplinaridade. Com isto, o Ensino/Aprendizagem da Física deve ser estruturado através de uma prática Interdisciplinar, propondo uma integração das diferentes áreas do conhecimento, levando a sua unificação, cooperação e troca de informações, cabendo, portanto, ao professor iniciar esse processo.
\end{abstract}

Palavras-chaves: Ensino/Aprendizagem; Multidisciplinaridade; Interdisciplinaridade; Transdisciplinaridade.

\section{A MULTIDISCIPLINARY, INTERDISCIPLINARY OR TRANSDISCIPLINARY PEDAGOGY TO THE TEACHING/LEARNING OF PHYSICS}

\begin{abstract}
Physics is a science that studies natural phenomena and it is always searching solutions and causes of how these phenomena influence our lives as a discipline of the school curricula. As we see the importance of Physics, the difficulty that teachers find to work with it, in a formal way, in a context involving interactivity, it is proposed three pedagogical levels: Multidisciplinarity, Interdisciplinarity and Transdisciplinarity. This approach has as its main objectives: transform the teaching/learning of Physics more dynamic; identify the difficulties presented by students and teachers in this process; propose methods to structure the concepts of this subject matter and provide a more interactive learning. The core of Physics in the school curricula, its importance for education, as well as, its contents within its context, and globalization skills for development, a pedagogical practice that unites such characteristics is the interdisciplinarity. Along with it, the Physics teaching/learning must be structured based on interdisciplinarity, which must propose an integration of the
\end{abstract}


different areas of knowledge, taking to its unification, cooperation and exchange of information, putting the teacher to start the process.

Key words: teaching/learning; multidisciplinarity, interdisciplinarity; transdisciplinarity. 


\section{UMA PEDAGOGIA MULTIDISCIPLINAR, INTERDISCIPLINAR OU TRANSDISCIPLINAR PARA O ENSINO/APRENDIZAGEM DA FÍSICA}

\section{INTRODUÇÃO}

A ciência procura discutir os princípios básicos dos fenômenos que ocorrem na natureza, procura descobrir as causas desses fenômenos e como eles influenciam nossa vida, tendo como objetivo único a melhoria das condições de vida da humanidade. A Física é uma disciplina do currículo escolar, sendo também uma ciência que estuda a natureza, discutindo seus fenômenos, causas e como eles influenciam na vida das pessoas. $\mathrm{O}$ Ensino/Aprendizagem dessa disciplina direciona-se aos conceitos básicos de movimento, as forças, a energia, o calor, o som, a luz, a eletricidade, os átomos, etc, questões que passaram a ser de grande importância para a compreensão de outras áreas de conhecimento. Constatando toda essa abrangência e interação dessa disciplina de forma epistemológica com as diferentes áreas e a dificuldade dos professores para lecioná-la mais precisamente de maneira contextualizada/globalizada, o que possibilitaria ao aprendiz construir competências relacionadas às múltiplas inteligências, de maneira que 0 Ensino/Aprendizagem lhe proporcionaria inúmeros conhecimentos para toda a sua vida. Dessa forma, propõem-se três níveis de práticas pedagógicas para a integração da Física com as outras disciplinas do currículo escolar: Multidisciplinaridade; Interdisciplinaridade ou Transdisciplinaridade.

\section{A FÍSICA COMO CIÊNCIA}

O objetivo único da ciência é a melhoria das condições de vida de toda a humanidade, sendo também uma forma de olhar o mundo. Ela procura discutir os princípios básicos dos fenômenos que ocorrem na natureza, assim como também procura descobrir as causas desses fenômenos e como eles influenciam nossa vida. Segundo Máximo e Alvarenga (2003) a ciência divide-se em:

Ciências vivas - estudam os fatos e coisas relacionados com a vida. Ciências físicas - estudam os conceitos e as coisas inanimadas. Ciências humanas - estudam os fatos relacionados mais perto com o homem. As duas primeiras subdivisões são conhecidas como ciências naturais, por tratarem de fatos que ocorrem na natureza.

Uma área de Ciências físicas que está diretamente relacionada com fenômenos presentes em todos os momentos de nossa vida é a Física - palavra de origem grega physiké, que significa "natureza”. Máximo e Alvarenga (2003 op.cit.) colocam que a "física é a ciência que estuda a natureza", com a preocupação de nos direcionar ao conhecimento dos fenômenos naturais, conhecimentos referentes a um novo mundo que vem sendo criado pelo homem ampliam cada vez mais o campo da Física, tornando nossas vidas profundamente envolvidas por ela. A Física direciona-se principalmente a conceitos básicos, tais como o movimento, as forças, a energia, a matéria, o calor, o som, a luz, a eletricidade, os átomos, etc (MÁXIMO e ALVARENGA 2003 op.cit.), questões que passaram a ser de total importância para a compreensão de outras áreas de conhecimento, assim como muitas teorias estudadas na química, matemática, biologia, sociologia e em 
vários outros ramos são necessários e indispensáveis para melhor entendimento Ensino/Aprendizagem - da Física.

\section{NÍVEIS PEDAGÓGICOS EM DISCUSSÃO NO ENSINO/APRENDIZAGEM DA FÍSICA}

Tendo em vista toda essa abrangência e interação da Física de forma epistemológica com as diferentes áreas, o desenvolvimento do Ensino/Aprendizagem dessa disciplina merece uma especial atenção, ou seja, um desenvolvimento que possibilite ao aprendiz construir competências relacionadas às múltiplas inteligências, de maneira que o Ensino da Física lhe proporcionará inúmeros conhecimentos para toda à sua vida. Perrenoud (1999, p.35) destaca que "toda competência está fundamentalmente ligada a uma prática social de certa complexidade. Não a um gesto dado, mas sim a um conjunto de gestos, posturas e palavras inscritos na prática que lhes confere sentido e continuidade”.

Estabelecer como o Ensino/Aprendizagem da Física deve ser trabalhado dentro de uma sala de aula, em toda a instituição escolar, ou melhor, em toda a vida do aluno, é cada vez mais um grande desafio para os professores que lecionam essa disciplina. Hernández e Ventura (1998, p.45) mostram que:

Realizar uma nova conexão entre a teoria e a prática na escola foi comprovar se estava sendo realizado um ensino globalizado. A intenção de que o aluno globalize os conteúdos e as aprendizagens é uma das orientações expressas pela atual reforma educativa, e também uma preocupação do professorado, pela adequação de seu trabalho à realidade social e cultural contemporânea.

As definições teóricas conceituais sobre as relações entre as diferentes disciplinas se podem dar em três níveis de organização: Multidisciplinaridade; Interdisciplinaridade e mais recentemente a nova Transdisciplinaridade. As discussões acerca desses temas não são novas (surgem no Brasil na década de 70), seja nas instituições de Ensino Fundamental, Médio e também no meio acadêmico. Essas discussões são bastante relevantes para enriquecer o Ensino/Aprendizagem de qualquer disciplina, em especial ao Ensino da Física no Ensino Médio, que está em discussão neste trabalho, implicando uma reflexão e um aprofundamento de estudo em cima destes temas em questão.

Para mostrar as diferenças conceituais da Multi, Inter e Transdisciplinaridade, nos propomos a colocar em debate essas definições teórico-pedagógicas, relacionando-se com práticas no Ensino Fundamental e no Médio, e principalmente com o Ensino da Física, visto a necessidade que vem sendo sentida de integrar as outras disciplinas com a Física, à realidade do Ensino/Aprendizagem das mesmas no Brasil, em todos os seus níveis. FRIGOTTO (1995ª , p.26) destaca que:

O Ensino convive com a contradição que historicamente existe em seu interior. De um lado, coloca-a a serviço da formação de elites dirigentes e, de outro lado, produz conhecimentos críticos para a interpretação das relações sociais contraditórias que conduzem a seu enfrentamento e transformação. Neste espaço, a organização 
curricular fragmentada e desarticulada, disciplinar, reflete a cisão histórica das atividades humanas imposta pelo modelo industrial à maioria das populações.

Discutindo a organização fragmentada do conhecimento nas escolas, Manacorda (1991) e Almeida Filho (1997, p.36) abordam que "o conhecimento veiculado nas escolas vem sendo organizado de forma tão estanque e fragmentado como a organização do trabalho industrial que coloca o indivíduo como objeto de ação parcial e obriga-o a constituir-se em um homem dividido, alienado, desumanizado. A realidade social e científica da modernidade é marcada por esta fragmentação”.

Ultimamente, em educação, muito se ouve falar em Multi, Inter e Transdisciplinaridade. Uma das questões que se coloca para discussão é a das diferenças de fundo entre esses conceitos. É preciso identificar, conceitualmente, analogias entre eles. A idéia de integração e de totalidade que aparentemente perpassa estes conceitos tem referenciais teórico-filosóficos diferentes e inconciliáveis. A prática do ensino dos professores sendo transdisciplinar, é diferente da prática de Ensino dos professores de forma interdisciplinar ou multidisciplinar e muito diferente da prática dos professores de maneira puramente disciplinar, do Ensino da Física.

\section{MULTIDISCIPLINARIDADE}

A Multidisciplinaridade trata da integração de diferentes conteúdos de uma mesma disciplina, porém sem nenhuma preocupação de seus temas comuns sob sua própria ótica, articulando algumas vezes bibliografia, técnicas de ensino e procedimentos de avaliação de conteúdos. Nogueira (2001, p. 140) mostra que "não existe nenhuma relação entre as disciplinas, assim como todas estariam no mesmo nível sem a prática de um trabalho cooperativo". E Almeida, (1997, p. 86) acrescenta "Poder-se-ia dizer que na Multidisciplinaridade as pessoas, no caso as disciplinas do currículo escolar, estudam perto, mas não juntas. A idéia aqui é de justaposição”.

Na Multidisciplinaridade recorremos a informações de várias matérias para estudar um determinado elemento, sem a preocupação de interligar as disciplinas entre si. Neste caso, cada matéria contribui com suas informações pertinentes ao seu campo de conhecimento, sem que houvesse uma real integração entre elas. Essa forma de relacionamento entre as disciplinas é a menos eficaz para a transferência de conhecimentos para os alunos, visto que não ocorre nenhuma relação de trabalho cooperativo entre as disciplinas, sem troca de informações, de diálogo (as disciplinas são tratadas separadamente). 


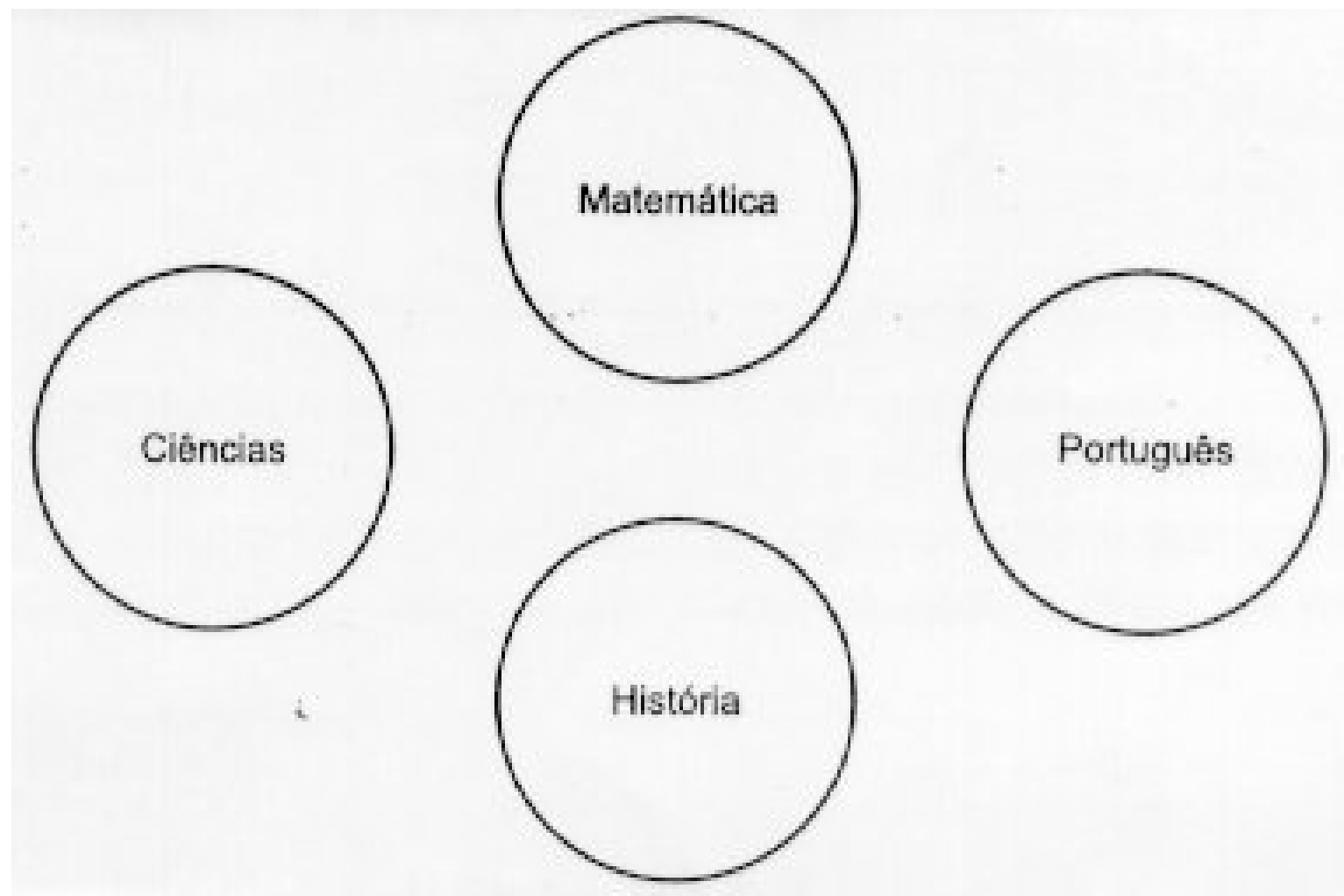

Esquema 01 - Multidisciplinaridade

FONTE: Nildo Ribeiro Nogueira (2001)

\section{INTERDISCIPLINARIDADE}

$\mathrm{Na}$ Interdisciplinaridade, essas discussões tomaram corpo nos anos setenta, propondo desde daí uma integração teórica e prática numa perspectiva da totalidade. Frigotto (1995a op.cit, p. 55) defende que a Interdisciplinaridade é "uma necessidade relacionada à realidade concreta, histórica e cultural, constituindo-se assim como um problema ético-político, econômico, cultural e epistemológico”. Assim como também destaca:

A Interdisciplinaridade se apresenta como problema pelos limites do sujeito que busca construir o conhecimento de uma determinada realidade e, de outro lado, pela complexidade desta realidade e seu caráter histórico. Todavia esta dificuldade é potencializada pela forma específica que os homens produzem a vida de forma cindida, alienada, no interior da sociedade de classes.

Nesta pedagogia existe uma real cooperação e troca de informações na sala de aula, aberto ao diálogo e ao planejamento. A fragmentação e compartimentação das diferentes disciplinas não contarão mais, a questão problema levará à unificação do conhecimento. "É necessária uma coordenação que integre objetivos, atividades, procedimentos, atitudes, planejamentos e que proporcione o intercâmbio, a troca, o diálogo, etc”. (NOGUEIRA, op.cit. p. 143). As disciplinas interagem entre si em distintas conexões, existe uma coordenação. O professor tentará formar o seu aluno a partir de tudo que ele estudou na sua vida. O Ensino/Aprendizagem baseado na Interdisciplinaridade 
proporciona uma aprendizagem bem estruturada e rica, pois os conceitos estão organizados em torno de unidades mais globais, de estruturas conceituais e metodológicas compartilhadas por várias disciplinas, cabendo ao aluno a realização de sínteses sobre os temas estudados.

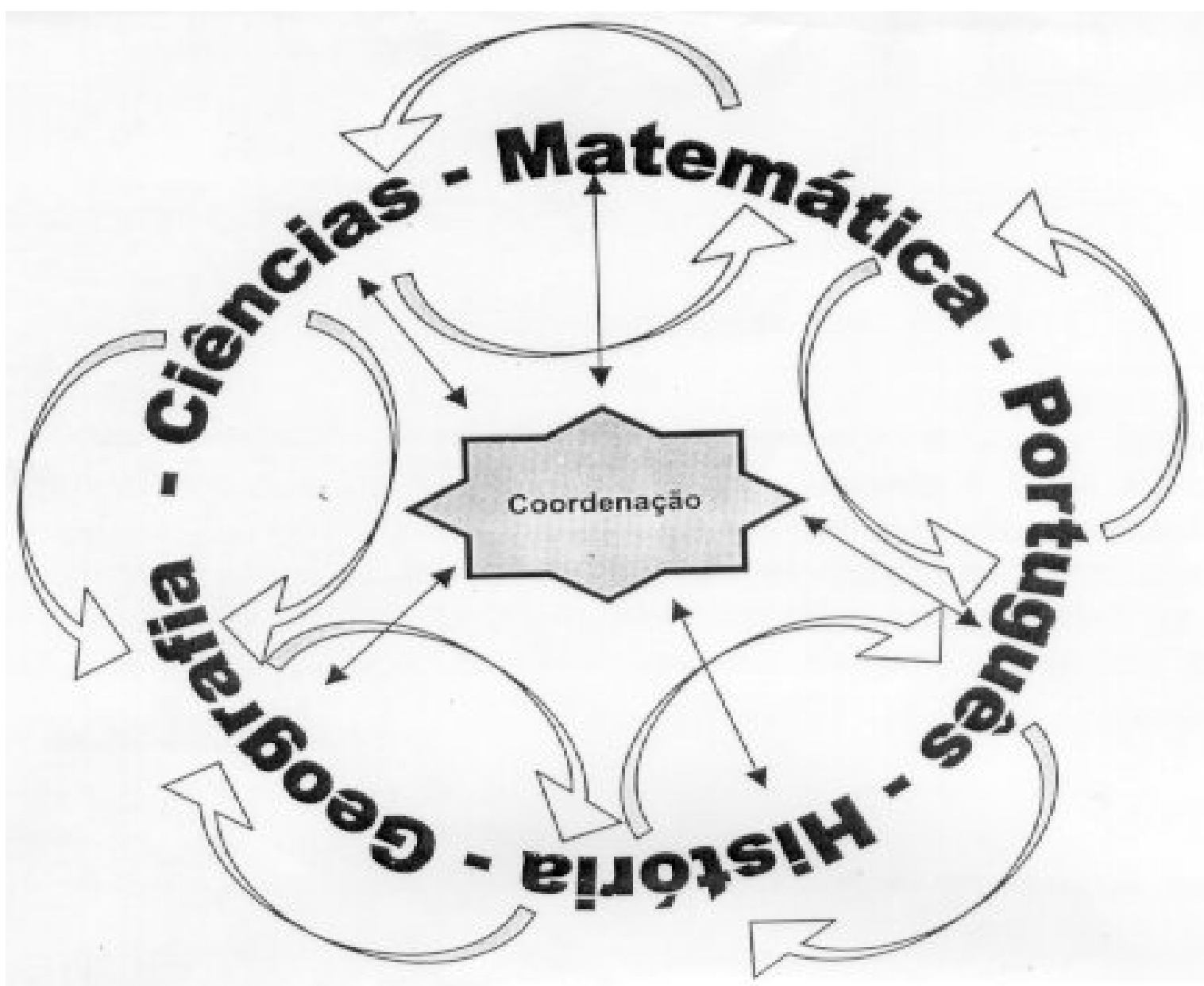

Esquema 02 - Interdisciplinaridade

FONTE: Nildo Ribeiro Nogueira (2001)

\section{TRANSDISCIPLINARIDADE}

Quanto à Transdisciplinaridade, ela é uma pedagogia de educação proposta recentemente, com vinculação à complexidade, ao pensamento complexo e epistêmico, sendo tratado com muita propriedade por Edgar Morin. Nesta pedagogia, as relações não iriam apenas de integração das diferentes disciplinas. Esta nova elaboração do Ensino/Aprendizagem vai muito além; para ela não devem existir fronteiras entre áreas do conhecimento e à interação chega a um nível tão elevado que é praticamente impossível distinguir onde começa e onde termina cada disciplina.

Nesta pedagogia, as relações entre as disciplinas consistem em proporcionar aos alunos, aos adolescentes que vão enfrentar o mundo do terceiro milênio, uma cultura, que lhes possibilitará articular, religar, contextualizar, situar-se num contexto e, se possível, globalizar, reunir os conhecimentos que foram adquiridos em toda a sua vida. 
Nogueira (op.cit. p. 145), coloca que "a finalidade a ser atingida é comum a todas disciplinas e interdisciplinas”. A Transdisciplinaridade insere-se na busca atual de um novo paradigma para as ciências da educação, buscando como referenciais teóricos a teoria da complexidade, com a idéia de rede, ou de comunicação entre os diferentes campos disciplinares.

Morin (2002), acredita que:

Para promover uma nova transdisciplinaridade precisamos de um paradigma que, certamente, permite distinguir, separar, opor e, portanto, disjuntar relativamente estes domínios científicos, mas que, também, possa fazê-los comunicarem-se entre si, sem operar a redução. O paradigma da simplificação (redução-disjunção) é suficiente e mutilante. Torna-se necessário um paradigma de complexidade que, ao mesmo tempo disjunte e associe, que conceba os níveis de emergência da realidade sem reduzi-los às unidades elementares e às leis gerais.

Esse novo paradigma da complexidade e a Transdisciplinaridade implicam na reforma do pensamento dentro do processo de ensino/aprendizagem - aqui se direciona ao da disciplina Física - traz consigo causa/conseqüências existenciais, éticas e cívicas. Essa reforma do pensamento do Ensino/Aprendizagem da Física, portanto, deve gerar-se a partir dos próprios professores e não do exterior, também contém uma necessidade social-chave, que é colocada por Morin (op.cit., p. 34.) "formar cidadãos capazes de enfrentar os problemas de seu tempo". Edgar Morin destaca também (op.cit, p. 36.), “essa reforma deve começar no ensino dos professores”, ou seja, no processo da sua formação, nas universidades.

Esta prática exige uma nova postura daqueles que desenvolvem estudos científicos e daqueles que trabalham com o processo de construção do conhecimento nas instituições de educação, propondo uma mudança de pensamento de todo o sistema educacional, uma reforma na educação e conseqüentemente no Ensino/Aprendizagem de qualquer disciplina do currículo escolar. Portanto, há que se buscar construir outros referenciais que norteiem as práticas educativas, oportunizando aos estudantes atividades mais atraentes e contextualizadas.

\section{CONSIDERAÇÕES FINAIS}

O Ensino/Aprendizagem da Física requer uma teoria/prática pedagógica que venha a tornar esse processo mais dinâmico, possibilitando uma articulação, contextualização, religação e globalização dos conteúdos a serem desenvolvidos em sala de aula, de maneira que o aluno possa construir suas próprias competências, seu próprio conhecimento sobre os assuntos dessa disciplina e relacioná-la com as outras áreas do conhecimento. Dos três níveis teóricos/práticos pedagógicos apresentados: Multidisciplinaridade; Interdisciplinaridade e Transdisciplinaridade. A que mais possibilitou uma estruturação e enriquecimento do Ensino/Aprendizagem da Física, oportunizando aos estudantes atividades mais atraentes e contextualizadas é a Interdisciplinaridade, visto que, nesta pedagogia ocorre uma real cooperação e troca de informações na sala de aula, aberto ao diálogo e o planejamento. As disciplinas terão uma 
interação entre si em diferentes conexões, existindo, dessa forma, uma coordenação. $\mathrm{O}$ Ensino/Aprendizagem da Física baseado na Interdisciplinaridade proporciona uma aprendizagem bem mais estruturada e rica, pois os conceitos estão organizados em torno de unidades mais globais, de estruturas conceituais e metodológicas compartilhadas por várias disciplinas, cabendo ao aluno a realização de sínteses sobre os temas estudados. Assim, essa proposta pedagógica estruturada na Interdisciplinaridade para o ensino/Aprendizagem da disciplina Física, levando a unificação do conhecimento, deve, portanto, iniciar-se nos professores dessa disciplina do currículo escolar.

\section{BIBLIOGRAFIA CONSULTADA}

ALMEIDA FILHO, N. Transdisciplinaridade e saúde coletiva. Ciência \& Saúde Coletiva. II (1-2), 1997.

FRIGOTTO, G. A Interdisciplinaridade como necessidade e como problema nas ciências sociais. In: BIANCHETTI. L. , JANTSCH. A. Interdisciplinaridade: para além da filosofia do sujeito. Petrópolis: Vozes. 1995ª . p. 20- 62.

HERNÀNDEZ, Fernando; VENTURA, Monteserrat.In: A organização do currículo por projetos de trabalho. A globalização: um caminho entre a teoria e a prática.Trad. Jussara Haubert Rodrigues. 5.ed. Porto Alegre: Artes Médicas, 1998. p. 45-60.

HEWITT, Paul G.In: Física conceitual / 9.ed. Porto Alegre: Bookman, 2002. p.28-41.

MÁXIMO, A. R. da Luz. ALVARENGA, B. Álvares. In: Física - Coleção de olho no mundo do trabalho. A física no campo da ciência. São Paulo: Scipione. 2003. p. 7-18.

MANACORDA, M. A. Marx e a pedagogia moderna. São Paulo: Cortez, 1991. p.37-68.

MORIN, Edgar. Educação e complexidade: Os setes saberes e outros ensaios. São Paulo: Cortez, 2002.

NOGUEIRA, Nildo Ribeiro. Pedagogia dos projetos: uma jornada Interdisciplinar rumo ao desenvolvimento das múltiplas inteligências. São Paulo: Érica, 2001.

PERRENOUD, Philippe.In: Construir as competências desde a escola. Programas escolares e competências. Porto Alegre: Artes Médicas Sul, 1999. p. 35-52. 